Betrachtet man die nach diesem Schema in den Normalorten übrig bleibenden Fehler, so sieht man, was zunächst die Darstellung durch die Parabel anlangt, dass es nur der 6. Ort ist, der mit Entschiedenheit auf eine von der Parabel abweichende Bahn des Cometen hinweist. Aber dieser Normalort ist nur aus vier Beobachtungen abgeleitet, die in Rectascension etwa um ${ }^{\text {s }}{ }^{\text {Ben }}$ voinander abweichen, so dass demselben den anderen Normalorten gegenüber eigentlich ein geringeres Gewicht hätte gegeben werden sollen. Nimmt man aber dennoch die Abweichung der Bahn von der Parabel als thatsächlich vorhanden an, so ist es jetzt, wie die Darstellung durch die zweite Grenzellipse zeigt, nur wieder ein Ort, und zwar der 3., auf welchen die
Excentricität den grössten Einfluss hat, so dass man sogar, wenn man diesen ausser Acht lassen würde, die Excentricität noch um vieles kleiner annehmen und damit die Umlaufszeit um ein Bedeutendes herabsetzen könnte, ohne eine wesentlich schlechtere Darstellung der Normalorte zu erlangen, als sie die wahrscheinlichste Ellipse giebt. Aber auch dieser Ort kann nicht als der sicherste betrachtet werden, da von den I 2 Beobachtungen, aus denen er ab. geleitet wurde, 4 in Rectascension vernachlässigt werden mussten und auch die ubrigen noch um circa $\mathrm{I}^{\mathrm{s}}$ von einander differiren. Es können daher für die Excentricität sowie fur die Umlaufszeit keine einigermaassen sichere Werthe angenommen werden.

\title{
Berichtigung zu dem Verzeichniss der Cometenbahnen in A. N. 2665-66.
}

In Folge einiger in den ersten Publicationen über die Eatdeckung des grossen September-Cometen I 882 II vorgekommenen Ungenauigkeiten, deren spätere anderweitige Richtigstellung von mir ïbersehen worden ist, bedürfen die in meiner Uebersicht über die neueren Cometenbahnen enthaltenen Angaben über die erste Sichtbarkeit und die ersten Beobachtungen dieses Cometen einer Berichtigung. Die erste wirkliche astronomische Beobachtung des Cometen (der in Europa zuerst durch die Entdeckung von Cruls am r I. Sept. in Rio de Janeiro bekannt wurde) ist ohne Zweifel die am Cap der guten Hoffnung Sept. 7 von Herrn Finlay angestellte (A. N. ro5.7 I), der dann erst die australischen Beob. achtungen in Windsor und Melbourne Sept. 8 und Sept. 9 folgten (A. N. I03.3 I3,349). Die erste Sichtbarkeit mit blossem Auge an verschiedenen Orten der Südhalbkugel fällt in die ersten Tage des September, só in Auckland und in Argentina (A. N. 104.129). Am Cap will man den Cometen schon am r. Sept. gesehen haben (wie den Astronomen der Cap-Sternwarte nachher bekannt wurde und nach einer gefalligen Mittheilung von Herrn Dr. Elkin), so dass es scheint, dass daselbst nicht blos die erste astronomische Beobachtung, sondern auch die erste Wahrnehmung des Cometen iberhaupt stattgefunden hat, sowie die in der Geschichte dieses Cometen wie der Cometen uberhaupt so wichtige und bisher einzig dastehende Beobachtung des Vorüberganges desselben vor der Sonnenscheibe durch die Herren Finlay und Elkin gleichfalls der Cap-Sternwarte zu danken ist.

$$
\text { Breslau } 1885 \text { Oct. I } 9 \text {. }
$$

Die Entdeckung des von Schmidt neben dem Cometen gesehenen und in der Bewegung demselben einigermassen folgenden Nebels oder Neben-Cometen fand nicht am 8. Oct., sondern am 9. Oct. statt, an welchem Tage nahe gleichzeitig. und unabhängig dieser Nebel auch auf der Südhalbkugel von Herrn Dr. Hartwig entdeckt wurde, nur etwa 4 Stunden später in einer 3 Stunden westlicheren Länge als in Athen (A. N. I06.23I). In der Uebersicht etc. ist diese zweite Entdeckung zwar citirt, aber als eine für die so höchst eigenthümlichen physischen Erscheinungen dieses Cometen wichtige Bestätigung der Schmidt'schen Wahrnehmungen nicht besonders und bestimmt genug hervorgehoben.

$\mathrm{Zu}$ den Bahnen älterer Cometen vor $\mathbf{1} 860$ ist sodann noch eine neuere definitive Bahnbestimmung des Cometen Nr. 1991854 II von Herrn Dr. H. Oppenheim nachzutragen, mit folgenden Elementen:

$$
\begin{aligned}
& T=\mathrm{r} 854 \text { März } 240^{\mathrm{h}} 28^{\mathrm{m}} 23^{\mathrm{s}} \text { M. Z. Paris } \\
& \pi=2 \text { I } 3^{\circ} 49^{\prime} \text { I }^{\prime \prime} .4 \\
& 8=315 \quad 2731.9\} \text { Mittl. Aequ. } 1854.0 \\
& i=823142.0 \\
& \log q=9.442580 \\
& \text { Rückläufig. }
\end{aligned}
$$

(Diss. inaugur. Göttingen I 870 ), welche nach gef. Mittheilung desselben aus 5 Normalörtern geschlossen sind und die sämmtlichen Beobachtungen umfassen.

F. G. Galle.

\section{Berichtigung zu Hansen's Tafel der Störungs-Coefficienten.}

Mit der allgemeinen Theorie der Pallas beschäftigt, bin ich auf folgende Fehler in der Tafel IV der Hansen' schen Abhandlung: »Entwickelung der negativen und ungeraden Potenzen etc. " gestossen:

In $D_{17}$ Arg. $9-9$ statt: 4.43645 und 4.3483 I lies: 5.43645 und 5.34831

in $D_{1}$ s Arg. $8-8$ statt: 5.2658 und 5.4787 lies: 6.2658 und 6.4787

Herr Prof. Scherbner hatte die Güte mir mitzutheilen, dass dieselben auf Druckfehlern beruhen.

Bogentiausen I 885 Oct. I 6 .

Dr. F. Bauschinger. 